\title{
Contenido y alcance jurisprudencial del bloque de constitucionalidad en Colombia*
}

\author{
Luis Andrés Fajardo Arturo** \\ Docente Investigador, \\ Universidad Sergio Arboleda
}

\begin{abstract}
Resumen
El Bloque de Constitucionalidad es uno de los más importantes aportes de la Constitución de 1991 al sistema jurídico colombiano. Su función fundamental es la de servir como instrumento de recepción del derecho internacional, garantizando la coherencia de la legislación interna con los compromisos ad extra del Estado y al mismo tiempo, servir de complemento para la garantía de los Derechos Humanos y el Derecho Internacional Humanitario en el país.

Sin embargo, dado que su regulación está exclusivamente a cargo de la jurisprudencia de la Corte Constitucional, y que son muy escasos los esfuerzos dirigidos a decantar de ella las reglas y subreglas al respecto, hoy en día, el desconocimiento sobre el valor, contenido y alcance del Bloque, se traducen en un riesgo para la seguridad jurídica del país y en el posible desconocimiento de sus derechos por parte de los ciudadanos.

Este artículo, fruto de una larga y metódica investigación, traduce el resultado de la identificación de las líneas jurisprudenciales constitucionales en materia de Bloque de Constitucionalidad, determinando fundamentalmente el valor jurídico y el contenido de dicho instrumento, en orden a establecer el valor, como fuente formal, de algunos tratados y sus interpretaciones, en el derecho interno.
\end{abstract}

\section{Palabras clave}

Derecho Constitucional, Bloque de Constitucionalidad, Jurisprudencia Constitucional.

\begin{abstract}
The Constitutional Body of Law (Bloque de Constitucionalidad) is one of the most important contributions of the Constitution of 1991 to the Colombian legal system. Its key role is to serve as a

Fecha de recepción del artículo: 15 de septiembre de 2007

Fecha de aprobación del artículo: 30 de octubre de 2007

"Este artículo es resultado del proyecto de investigación titulado Influencia del Sistema Interamericano de Protección de los Derechos Humanos en el Derecho Constitucional Colombiano; avalado y financiado por la Universidad Sergio Arboleda; ejecutado por el Grupo de las Casas, categoría B en Colciencias. Participaron en la investigación precedente a este artículo los estudiantes Alejandro Cerón Perdomo y Augusto Torregrosa Sánchez.

** Abogado Universidad Sergio Arboleda, DSU Droit International Public Université Panthéon-Assas, CEJI del Instituto de Altos Estudios Internacionales Universidad Paris II, Especialista en Derechos Humanos Universidad Alcalá de Henares. Docente Investigador, director del Área de Derechos Humanos y codirector del Grupo de las Casas, Universidad Sergio Arboleda.
\end{abstract}


receptive instrument of international law, ensuring consistency of domestic legislation with the commitments ad extra of the State, and at the same time, serve as a complement to guarantee human rights and IHL in the country.

However, since the jurisprudence of the Constitutional Court is solely responsible for its regulation, and very few efforts exist today to develop from it the corresponding rules and subrules, ignorance on the value, content and scope of the Body of Law, results in a risk to the country's legal security and possibly, the citizens' lack of knowledge about their rights.

This article, the product of a long and methodical investigation, explains the result of the identification of the constitutional jurisprudence lines in the area of the Constitutional Body of Law, essentially determining the legal status and content of this instrument, in order to establish value, as a formal source, of some treaties and some of their interpretations, in domestic law.

\section{Key words}

Constitutional law, Constitutional Body of Law, constitutional case-law.

\section{Problema de investigación}

El presente artículo es el resultado de un proyecto de investigación titulado "La influencia del Sistema Interamericano de Protección de los Derechos Humanos, en el Derecho Constitucional Colombiano". Se trata del resultado de la investigación sobre las líneas jurisprudenciales relacionadas con el primer objetivo propuesto en el proyecto: la determinación de la naturaleza y contenido del Bloque de Constitucionalidad en Colombia.

El Bloque de Constitucionalidad es uno de los más importantes y, a la vez, menos claros instrumentos que incluyó la Carta Política de 1991 al sistema normativo colombiano. Se trata de una herramienta de integración del derecho internacional en el orden constitucional colombiano y por ende, de un medio de ampliación de la normatividad constitucional, para el control de la normatividad jerárquicamente inferior e, igualmente, para la garantía de los derechos humanos en el país.

Pese a su enorme importancia y a la gran complejidad que implica, no existe certeza sobre qué es y qué contiene finalmente el Bloque de
Constitucionalidad. A pesar de la aparente simplicidad del art. 93 superior, el acoplamiento de la normatividad internacional y las reglas para su exigibilidad directa en el ámbito constitucional interno no son nada simples.

Es este el problema específico de esta etapa de la investigación: qué es, qué contiene y qué valor tiene el Bloque de Constitucionalidad. Por ende el objetivo que se pretende lograr con este artículo es el de definir el alcance y contenido del Bloque. Para hacerlo, se hace indispensable conocer las respuestas de la única institución facultada, interprete autorizada de la Constitución, quien se ha convertido, como efecto de su propia jurisprudencia, en un órgano capaz de producir decisiones con valor de precedente judicial obligatorio.

Este "cambio de la cultura jurídica" como lo llamaría Diego López (2006), tiene como efecto, el que hoy en Colombia, sea imprescindible para los estudiosos del derecho, conocer las reglas y subreglas establecidas jurisprudencialmente por la Corte Constitucional, pues de otra forma, el solo conocimiento de los textos legales, es insuficiente para la realización de análisis serios $\mathrm{y}$ argumentaciones válidas, por lo menos en cuanto al derecho constitucional. 
Ahora bien, si bien la jurisprudencia de la Corte es importante en cuanto a la interpretación de los derechos fundamentales, por ejemplo, lo es aún más en cuanto a la determinación de las herramientas constitucionales, y dentro de ellas, una de las más importantes es, sin lugar a dudas, el Bloque de Constitucionalidad.

En ese sentido el texto que a continuación se presenta, tiene la finalidad de constituirse en una guía clara y completa, sobre la forma en que la Corte Constitucional entiende el Bloque, los instrumentos que hacen parte de ella y el valor de fuente formal en el derecho colombiano, de los instrumentos internacionales, que la Corte ha incluido en el Bloque.

\section{Método}

El presente artículo es el resultado de más de 8 meses de investigación, con un método general consistente en la construcción de temas jurisprudenciales o identificación de precedentes constitucionales.

La Metodología de trabajo, se dividió fundamentalmente en tres etapas. La primera de ellas estuvo dirigida a construir una ficha de recolección de información, a través de la cual fuese posible adquirir toda la información necesaria de las sentencias de la Corte Constitucional, a fin de determinar el concepto, contenido y alcance de los instrumentos integrantes del Bloque de Constitucionalidad.

Posteriormente se empezó a recolectar la información de las sentencias. La recolección de información se hizo año tras año, empezando en 1995, año en que por primera vez se le dio contenido al Bloque. Se recolectó información de las sentencias de cada año y luego, al completar dos años, se confirmaba la información recolectada a través del envío de Derechos de Petición a la Relatoría de la Corte Constitucional para que confirmara que no existía ninguna otra sentencia que hiciera referencia al Bloque de Constitucionalidad.
El tiempo de recolección de sentencias y procesamiento de información de las fichas duró un poco más de 6 meses, puesto que la intención era la de construir líneas jurisprudenciales completas, es decir, que no se trabajaron desde la más reciente a la más antigua, lo cual sin duda hubiera ahorrado algo de tiempo, sino que la intención era escudriñar profundamente la jurisprudencia, buscando total claridad sobre el tema, analizando las posibles variaciones, sin dejar de lado ninguna sentencia.

El trabajo de recolección y procesamiento de la información estuvo dirigido por el investigador principal y fue realizado completamente por parte de Jose Augusto Torregrosa y Gustavo Cerón, entonces destacados estudiantes de la Escuela de Derecho y actualmente abogados, quienes realizaron sus tareas como auxiliares de investigación en este proyecto. Su valioso trabajo, la puntualidad de sus entregas, la motivación conque realizaron sus tareas, es lo que ha hecho posible que esta investigación pueda presentar este artículo de resultados.

Finalmente, durante dos meses, el equipo se dedicó a establecer, con la información recolectada en las fichas, las líneas jurisprudenciales en materia de Bloque de Constitucionalidad. El resultado de ese esfuerzo, es lo que a continuación se presenta.

\section{Noción y alcance del bloque de constitucionalidad}

\section{Noción del bloque de constitucionalidad}

El concepto de bloque de constitucionalidad tiene su origen en la práctica del Consejo Constitucional francés, el cual considera que, como el Preámbulo de la Constitución de ese País hace referencia al Preámbulo de la Constitución derogada de 1946 y a la Declaración de Derechos del Hombre y del Ciudadano de 1789; esos textos son también normas y principios de valor constitucional que condicionan la validez de las leyes. Según la doctrina francesa, estos textos forman entonces un bloque con el articulado de 
la Constitución, de suerte que la infracción por una ley de las normas incluidas en el bloque de constitucionalidad comporta la inexequibilidad de la disposición legal controlada (Corte Constitucional, Sent. C-225/95). ${ }^{1}$

Para empezar a construir una definición en Colombia, habría que decir, como dice el profesor Uprimny (2000), que "el bloque de constitucionalidad hace referencia a normas constitucionales que no se encuentran en la constitución política."(p.2) es decir, que forman una ampliación material de la Carta Fundamental.

El Bloque de Constitucionalidad ha sido definido por parte de la doctrina (Estrada-Vélez, 2005), como: "el conjunto de normas que configuran una unidad constitucional que es empleada como parámetro de constitucionalidad de las restantes normas del ordenamiento" (p.79).

Ese es en efecto el sentido clásico del Bloque de Constitucionalidad, tal como fue concebido desde sus orígenes franceses. Rubio-Llorente (1991) explica cómo en la doctrina francesa "el Bloc de Constitutionalité, se utiliza para designar el conjunto de normas que el Consejo Constitucional aplica en el control previo de constitucionalidad de las leyes" (p.105).

En la jurisprudencia nacional se han manejado diferentes definiciones de Bloque de Constitucionalidad, evolucionando en la complejidad del concepto a través del tiempo, así la Corte en 1995, en un concepto básico muy reiterado, lo define simplemente como:

(...) aquellas normas y principios que, sin aparecer formalmente en el articulado del texto constitucional, son utilizados como parámetros del control de constitucionalidad de las leyes, por cuanto han sido normativamente integrados a la Constitución, por diversas vías y por mandato de la propia Constitución. Son verdaderos principios y reglas de valor constitucional, esto es, son normas situadas en el nivel constitucional, a pesar de que puedan a veces contener mecanismos de reforma diversos al de las normas del articulado constitucional stricto sensu. (Sent. C-225/ 95$, p. 60$)^{2}$

Posteriormente, en 2003, de forma más específica en cuanto a la finalidad del Bloque de Constitucionalidad, la Corte dijo que:

(...) las normas del bloque operan como disposiciones básicas que reflejan los valores y principios fundacionales del Estado y también regulan la producción de las demás normas del ordenamiento doméstico. Dado el rango constitucional que les confiere la carta, las disposiciones que integran el bloque superior cumplen la cuádruple finalidad que les asigna Bobbio, a saber, servir de i) regla de interpretación respecto de la dudas que puedan suscitarse al momento de su aplicación; ii) la de integrar la normatividad cuando no exista norma directamente aplicable al caso; iii) la de orientar las funciones del operador jurídico, y iv) la de limitar la validez de las regulaciones subordinadas. (Sent. C-067/03, p.18).

En ese sentido, en Colombia la noción de Bloque de Constitucionalidad sobrepasa la visión clásica de una herramienta de control de normas, busca unificar el sistema normativo nacional, y afecta, como se verá a continuación, el alcance de los recursos constitucionales sobre derechos humanos. La acción de Tutela, por ejemplo, si bien no puede invocar directamente la violación del Bloque, sí puede acudir a la interpretación más amplia de los derechos fundamentales a través del Bloque.

\section{Incorporación al bloque de constitucionalidad}

La noción del Bloque de Constitucionalidad se fundamenta en el Artículo 93 de la Constitución. 
$\mathrm{Al}$ analizar este artículo, la Corte ha manifestado que existe una relación diferenciada entre los dos incisos que lo componen. Por una parte, el primer inciso "permite incorporar ciertos derechos y principios al bloque de constitucionalidad, incluso cuando éstos no han sido reconocidos por el articulado constitucional, pero para ello se requiere que sean derechos no limitables en estados de excepción", mientras que en el segundo inciso "tiene otra finalidad pues esa norma completa y dinamiza el contenido protegido de un derecho que ya está consagrado en la Carta, puesto que, conforme a ese inciso, tal derecho debe ser interpretado de conformidad con los tratados ratificados por Colombia" (Sent. T-1318/01).

Esta tesis, sostenida en la sentencia T-1319 de 2001 y reiterada por la Corte en sentencias de unificación como 058/03 y 067/03, se traduce en que por una parte, el art.93 permite la inclusión de nuevos derechos en el corpus iuris constitucional $y$, por otra, para los derechos reconocidos en la Carta, hace necesaria una valoración a la luz de los tratados firmados por Colombia. Dice la Corte: "El inciso segundo, por su parte, ordena que los derechos y deberes previstos en la Constitución se interpreten de conformidad con los tratados internacionales sobre derechos humanos ratificados por Colombia. Así, esta vía de incorporación está sujeta a que el derecho humano o el deber, tengan su par en la Constitución pero no requiere que el tratado haga referencia a un derecho no suspendible en estados de excepción" (Sent. T-1319/01, p.17).

Pero la posición más interesante sostenida en la T-1319/01, que se reitera en varias sentencias, es aquella según la cual, el inciso 2 del Art. 93 establece una forma de incorporación vía interpretación "en que ha de fundirse la norma nacional con la internacional y acogerse la interpretación que las autoridades competentes hacen de las normas internacionales e integrar dicha interpretación al ejercicio hermenéutico de la Corte". ${ }^{3}$

En ese sentido, la Corte garantiza el cumplimiento de los deberes internacionales del Estado, al coordinar el derecho interno con las normas internacionalmente acordadas. Esto representa, no solamente un avance en la protección de los derechos fundamentales, sino a la vez, una herramienta que garantiza la integración del derecho internacional en el derecho interno de una manera eficiente.

A ese respecto, vale la pena anotar que, como lo sostienen algunos doctrinantes, entre ellos Ramelli Arteaga (2003), el Bloque de Constitucionalidad surgió por "la necesidad de armonizar el contenido del principio de supremacía constitucional con el de primacía del derecho internacional" (p. 134).

Ramelli (2003) sostiene que el debate se suscita en torno al principio de supremacía de la Constitución y las normas de esta que le dan primacía al derecho internacional y que la solución adoptada por la constituyente fue acoger la figura del Bloque de Constitucionalidad de origen francés.

En ese sentido, para zanjar la discusión sobre el valor del derecho internacional en el derecho colombiano, la Corte ha establecido, desde sus inicios, en la sentencia C-225/95 (pp. 59 y 60), que no obstante los convenios de derecho internacional prevalezcan en el orden interno, no significa que obtengan el carácter de normas supraconstitucionales,

(...) el único sentido razonable que se puede conferir a la noción de prevalencia de los tratados de derechos humanos y de derecho internacional humanitario (CP arts. 93 y 214 numeral $2^{\circ}$ ) es que éstos forman con el resto del texto constitucional un "bloque de constitucionalidad", cuyo respeto se impone a la ley. En efecto, de esa manera se armoniza plenamente el principio de supremacía de la Constitución, como norma de normas ( $\mathrm{CP}$ art. $\left.4^{\circ}\right)$, con la prevalencia de los tratados ratificados por Colombia, que reconocen los derechos humanos y prohíben su limitación en los estados de excepción (CP art. 93)." 


\section{Requisitos de operación del bloque de constitucionalidad}

\section{Requisitos para que opere el bloque de constitucionalidad vía prevalencia:}

La validez del Bloque de Constitucionalidad en Colombia se debe a que, según lo ha venido sosteniendo la Corte de forma reiterada, "existe remisión expresa de la Constitución" (Sent. C$578 / 95$, p.28), y en ese sentido, para que una norma sea validamente usada como parte del Bloque, debe cumplir con los requisitos que exige el Art. 93 de la Carta.

Para que opere "la prevalencia en el orden interno de ciertos contenidos de los tratados de derechos humanos ratificados por Colombia es necesario que se den los dos supuestos a la vez, de una parte, el reconocimiento de un derecho humano, y de la otra que sea de aquellos cuya limitación se prohíba durante los estados de excepción" Esta posición establecida desde la sentencia C-295/93 constituye un precedente fuertemente reiterado ${ }^{4}$, aunque, como se verá más adelante, este requisito no ha sido exigido estrictamente en todos los casos.

Por su parte, el inciso segundo del artículo 93 constitucional ordena que los derechos y deberes previstos en la Constitución deben interpretarse de conformidad con los tratados internacionales sobre derechos humanos ratificados por Colombia. En esta forma de incorporación, el derecho humano o el deber, ha de tener su par en la Constitución pero no requiere que el tratado se refiera a uno no suspendible en estados de excepción.

Es decir, para que opere el Bloque de Constitucionalidad vía interpretación, es necesario que el derecho humano tenga su par en la Constitución. Esta tesis ha sido sostenida por la Corte, en particular al analizar la inclusión de los convenios de la OIT en el Bloque de Constitucionalidad en la sentencia C-09/2000, y posteriormente ha sido ratificada en una extensa

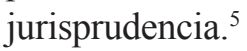

\section{Bloque de constitucionalidad en sentido strictu y lato:}

Como lo explica Mónica Arango (2004) "La Corte fue poco a poco precisando el concepto del Bloque de Constitucionalidad para entender que existen dos sentidos del mismo". En efecto, la Corte a partir de 1997, empieza a distinguir entre el sentido stricto y el sentido lato del Bloque, para diferenciar entre aquellos instrumentos normativos que se sumaban como fuentes materiales formales al texto de la Constitución y aquellos que se adherían como fuentes de interpretación de las normas constitucionales.

Es interesante destacar que el sentido en que primeramente distinguió la Corte entre stricto y lato sensu se refería a un criterio formal de pertenencia, ajustado al primero o segundo inciso del Art. 93. Sin embargo, en la práctica, la Corte ha utilizado ciertos instrumentos que en realidad no cumplen con los requisitos del primer inciso del Art.93, pero que harían parte del Bloque stricto sensu, puesto que, como los convenios OIT, más que criterios de interpretación son fuentes de obligaciones que se suman al articulado constitucional.

En la sentencia C-191/98, con ponencia del doctor Eduardo Cifuentes Muñoz, se afirma que "resulta posible distinguir dos sentidos del concepto de bloque de constitucionalidad. En un primer sentido de la noción, que podría denominarse bloque de constitucionalidad stricto sensu, se ha considerado que se encuentra conformado por aquellos principios y normas $d e$ valor constitucional, los que se reducen al texto de la Constitución propiamente dicha y a los tratados internacionales que consagren derechos humanos cuya limitación se encuentre prohibida durante los estados de excepción (C.P., artículo 93)". Con respecto a la acepción estricta del concepto de bloque de constitucionalidad, esta Corporación ha sentado la siguiente doctrina:

Como vemos, el bloque de constitucionalidad está compuesto por aquellas 
normas y principios que, sin aparecer formalmente en el articulado del texto constitucional, son utilizados como parámetros del control de constitucionalidad de las leyes, por cuanto han sido normativamente integrados a la Constitución, por diversas vías y por mandato de la propia Constitución. Son pues verdaderos principios y reglas de valor consti-tucional, esto es, son normas situadas en el nivel constitucional, a pesar de que puedan a veces contener mecanismos de reforma diversos al de las normas del articulado constitucional stricto sensu. ( Sent. C-225/95) ${ }^{6}$

Más recientemente, la Corte ha adoptado una noción lato sensu del Bloque de Constitucionalidad, según la cual aquel estaría compuesto por todas aquellas normas, de diversa jerarquía, que sirven como parámetro para llevar a cabo el control de constitucionalidad de la legislación. Conforme a esta acepción, el bloque de constitucionalidad estaría conformado no sólo por el articulado de la Constitución sino, entre otros, por los tratados internacionales de que trata el artículo 93 de la Carta, por las leyes orgánicas y, en algunas ocasiones, por las leyes estatutarias. Sobre este punto, la Corporación se ha expresado como sigue:

Con arreglo a la jurisprudencia de esta Corporación, el bloque de constitucionalidad está compuesto por aquellas normas y principios que, sin aparecer formalmente en el articulado del texto constitucional, son utilizados como parámetros del control de constitucionalidad de las leyes. Ello bien porque se trata de verdaderos principios y reglas de valor constitucional, esto es, porque 'son normas situadas en el nivel constitucional', como sucede con los convenios de derecho internacional humanitario, o bien porque son disposiciones que no tienen rango constitucional pero que la propia Carta ordena que sus mandatos sean respetados por las leyes ordinarias, tal y como sucede con las leyes orgánicas y estatutarias en determinados campos. (Sent. C-658/97) ${ }^{7}$

En suma, es posible afirmar que aquellas normas que pertenezcan al denominado Bloque de Constitucionalidad lato sensu, se caracterizan por: "(1) ser parámetro para efectuar el control de constitucionalidad del derecho interno; (2) tener un rango normativo superior a las leyes ordinarias (en algunos casos son normas constitucionales propiamente dichas y, en otros casos, ostentan una jerarquía intermedia entre la Constitución y la ley ordinaria); y, (3) formar parte del bloque de constitucionalidad gracias a una remisión expresa efectuada por alguna disposición constitucional"(Sent. C-191/98). ${ }^{8}$

También expresa la corporación constitucional "el hecho de que algunas leyes pueden integrar el mencionado bloque de constitucionalidad en sentido lato, siempre que la propia Carta lo haya ordenado, en forma directa y específica, de manera que sus mandatos sean respetados por las leyes ordinarias y logren instituirse como parámetros de un control de constitucionalidad sobre las mismas" (Sent. C-708/99, p. 13, párr. 4). Esta condición se le ha otorgado a la ley estatutaria que regula los estados de excepción (Ley 137 de 1994), en la Sentencia C-578 de 1995, reiterándolo posteriormente, en la Sentencia C-191 de 1998.

La Corte aclara mediante un análisis más detallado el contenido del Bloque de Constitucionalidad en sentido lato, pues establece que, en principio, integran el bloque de constitucionalidad en este sentido: "(i) el preámbulo, (ii) el articulado de la Constitución, (iii) algunos tratados y convenios internacionales de derechos humanos (C.P. art. 93), (iv) las leyes orgánicas ${ }^{9}$ $\mathrm{y}$, (v) las leyes estatutarias ${ }^{10 "}$. "Por lo tanto, si una ley contradice lo dispuesto en cualquiera de las normas que integran el bloque de constitucionalidad la Corte Constitucional deberá retirarla del ordenamiento jurídico, por lo que, (...) la inexequibilidad de una disposición legal no sólo 
se origina en la incompatibilidad de aquella con normas contenidas formalmente en la Constitución"(Corte Constitucional, Sent. C-582/99). ${ }^{11}$

La sentencia SU-058/03, con ponencia de Eduardo Montealegre Lynett, sintetizó los conceptos de bloque de constitucionalidad stricto y lato sensu de la siguiente manera: "El contenido del bloque de constitucionalidad latu sensu, está definido de manera parcial en el artículo 93 de la Constitución. De acuerdo con el inciso primero, primarán en el ordenamiento interno, aquellos tratados relativos a derechos humanos y que prohíben su limitación durante los estados de excepción. En este orden de ideas, debe admitirse que las normas que cumplan con los requisitos mencionados, integran la Constitución" (p. 38).

En el ámbito laboral, la Corte ha manifestado que algunos convenios internacionales del trabajo forman parte del Bloque de Constitucionalidad en sentido lato (C.P., art. 93, inciso 2), lo cual significa que se constituyen en un referente para interpretar los derechos de los trabajadores y para darle plena efectividad al principio fundamental de la protección al trabajador (C.P., art. 1) y al derecho al trabajo (C.P. arts. $25 \mathrm{y}$ 53); además, corresponde a la Corte señalar los convenios internacionales del trabajo que forman parte del Bloque de Constitucionalidad en sentido estricto (C.P., art. 93, inciso 1), cuando determinen que el derecho humano que reconozcan no pueda ser limitado durante un estado de excepción o desarrolle tal prohibición. (Corte Constitucional, Sent. C-401/05)

En la misma sentencia, la Corte sostiene que los convenios de la OIT ratificados por Colombia son fuente principal y son aplicables directamente para resolver las controversias. Los convenios que integran el bloque de constitucionalidad en sentido lato orientan la interpretación de la norma suprema, y que aquellos convenios que forman parte del bloque de constitucionalidad en sentido estricto prevalecen en el orden interno. Así habrán de valorarlos especialmente los jueces y los funcionarios administrativos.
Las normas que componen el bloque de constitucionalidad.

Dado que la amplitud del concepto encierra una serie de normas, es importante indicar, que al menos en lo que corresponde al Bloque strictu sensu, hasta ahora la Corte ha considerado que hacen parte, una serie de derechos contenidos en instrumentos que en su mayoría, cumplen con los requisitos formales establecidos en la Carta, como es el caso de la Convención Americana de Derechos Humanos, y los tratados de la ONU en materia de Derechos Humanos. A continuación enumeramos estos instrumentos junto con la sentencia hito que los ha reconocido como parte del Bloque los siguientes instrumentos, los cuales, por ser tratados sobre derechos humanos intangibles, cumplen de plano con todos los requisitos. ${ }^{12}$

1. Convenios de Ginebra y Protocolo II sobre DIH, (C.C., C 574/92)

2. Convención Americana de Derechos Humanos, (C.C., T 260/99) ${ }^{13}$

3. Pacto Internacional de Derechos Sociales, Económicos y Culturales (PIDESC) y el Protocolo adicional de San Salvador, sobre derechos económicos, sociales y culturales (C.C., C 251/97) $)^{14}$

4. Pacto Internacional de Derechos Civiles y Políticos (C.C., T-256/00) ${ }^{15}$

5. Instrumentos De Protección De Los Derechos De Los Niños. (C.C., C-1068/02) ${ }^{16}$

En la C-1068/2002 se establece que los tratados internacionales que traten sobre los derechos de los niños y que hayan sido ratificados por Colombia hacen parte del Bloque de Constitucionalidad. Entre estos se encuentran:

Declaración de Ginebra de 1924 sobre los Derechos del Niño, Declaración de los Derechos del Niño adoptada por la Asamblea General de las Naciones Unidas el 20 de noviembre de 1959, y reconocida en la Declaración Universal de Derechos Humanos ${ }^{17}$, el Pacto internacional de Derechos Civiles y Políticos (en particular, en los artículos 23 y 24), La Convención Internacional 
Sobre los Derechos del Niño ${ }^{18}$; el Pacto Internacional de Derechos Económicos, Sociales y Culturales (en particular, en el artículo 10) y en los estatutos e instrumentos pertinentes de los organismos especializados y de las organizaciones internacionales que se interesan en el bienestar del niño. También, el Convenio 182 sobre "la prohibición de las peores formas de trabajo infantil" (C.C., C-118/06, P.14).

6. Convenios de la OIT que hacen parte del bloque (Corte Constitucional, Sent. C-038/04) ${ }^{19}$.

Es menester resaltar que, según la Corte no todos los convenios internacionales del trabajo debidamente ratificados por Colombia forman parte del bloque de constitucionalidad, esto es, que no ingresan in genere y automáticamente al bloque de constitucionalidad, sino que su incorporación al mismo es decidida de manera específica, atendiendo cada caso en concreto, por la Corte Constitucional, de acuerdo con su materia y con criterios objetivos. Lo anterior, puesto que algunos de estos convenios no reconocen ni regulan derechos humanos, sino aspectos administrativos, estadísticos o de otra índole no constitucional. Pero para la Corte es claro que algunos convenios deben necesariamente formar parte del Bloque de Constitucionalidad, puesto que protegen derechos humanos en el ámbito laboral (Corte Constitucional, Sent. C-401/05).

Algunos de los tratados hacen parte del bloque en sentido lato, ya que son un referente para interpretar los derechos de los trabajadores y darle plena efectividad al principio fundamental de la protección al trabajador y al derecho al trabajo. $\mathrm{Si}$ un Convenio prohíbe la limitación de un derecho humano durante un estado de excepción, corresponde a la Corte señalar específicamente si pertenece o no al Bloque en sentido estricto. (Corte Constitucional, Sent. T-285/06).

\section{Constitución de la OIT y convenios 87 y 98 de la OIT}

Se establece que dentro del bloque de constitucionalidad también procede incluir "la
Constitución de la OIT y los Convenios 87 y 98 sobre libertad sindical (tratado y convenios debidamente ratificados por el Congreso, que versan sobre derechos que no pueden ser suspendidos ni aún bajo los estados de excepción); además, los artículos pertinentes de la Declaración Universal de los Derechos Humanos, el Pacto Internacional de Derechos Económicos, Sociales y Culturales, y la Convención Americana de Derechos Humanos" (Corte Constitucional, Sent. T-568/99, p.28) ${ }^{20}$.

En esta sentencia, la Corte, haciendo una expresa referencia a la pertenencia al Bloque de los derechos consagrados en los convenios de la OIT, explica: "Los derechos de asociación, sindicalización y huelga, como se explicó anteriormente, forman parte de la normatividad constitucional por una razón doble: están expresamente consignados en la Carta, y ella integra a su texto los tratados internacionales sobre la materia" (p. 30).

Con respecto a estos convenios, el Auto 078/ 99. M.P. Carlos Gaviria Díaz, en el que se negó la solicitud de nulidad de la sentencia T-568/99, que integró dichos Convenios al Bloque de Constitucionalidad, manifiesta lo siguiente: "el bloque de constitucionalidad se usó para los fines precisos que señala el artículo 93 de la Carta Política: para interpretar el alcance de los derechos consagrados en ella "de conformidad con los tratados internacionales sobre derechos humanos ratificados por Colombia". Y los Convenios 87 y 98 son parte de la legislación interna en cuanto fueron debidamente ratificados (C.P. art, 53), por lo que son normas aplicables en cuya interpretación deben los jueces atender el criterio de los órganos de la OIT que son sus intérpretes legítimos y autoridades competentes para vigilar el cumplimiento de las obligaciones que se desprenden de la Constitución de la Organización Internacional del Trabajo".

Así las cosas, en distintas ocasiones la Corte le ha concedido a los convenios y tratados internacionales del trabajo, la naturaleza de 
normas constitutivas del Bloque por vía de interpretación, con el objetivo de servir de herramienta para desentrañar la naturaleza abierta e indeterminada de los conceptos jurídicos previstos en el Texto Superior ${ }^{21}$.

Según el análisis de la Corte a los Convenios, se ha establecido que el derecho de asociación sindical es un derecho fundamental y que por ende es susceptible de ser protegido mediante la tutela.

Convenio 169 de la OIT: Para la Corte (Sent. T-606/01, p. 20) la jurisdicción especial indígena no se encuentra únicamente establecida en la Constitución, ya que el Convenio 169 de la OIT (artículo 17 principalmente para este caso), se integra a la carta fundamental, pues hace parte del bloque de constitucionalidad en cuanto dicho Convenio contempla temas de derechos humanos, cuya limitación se encuentra prohibida aún durante los estados de excepción. Por tal razón, la infracción a las normas del Convenio 169 de la OIT puede ser motivo de tutela en cuanto afecten derechos fundamentales ${ }^{22}$.

Además, en la sentencia T-955/03, la Corte adicionó que debido a la ratificación de los Convenios de la OIT, Colombia se obliga a respetar los derechos de las comunidades afrocolombianas en cuanto sus condiciones sociales, culturales y económicas. Esto sin duda, representa algo más que el sentido lato del Bloque, puesto que adiciona una norma vía bloque de constitucionalidad, sin que cumpla con el requisito de ser irrestringible en estados de excepción.

También hacen parte del Bloque, según la sentencia C-1188/05, el Convenio de la OIT sobre la edad mínima, y el Convenio de la OIT sobre las peores formas de trabajo infantil.

Otros Convenios de la OIT que hacen parte del bloque de constitucionalidad: dentro de los Convenios que hacen parte del bloque también se encuentran los que tratan sobre derechos humanos fundamentales en el trabajo, así como los Convenios 29 y 105, relativos a la abolición del trabajo forzoso, como también las estadísticas del trabajo (Convenio 160), pasando por los asuntos de la simplificación de la inspección de los emigrantes (Convenio 21), de la inspección del trabajo (Convenios 81 y 129) y de la preparación de las memorias sobre la aplicación de convenios por parte del Consejo de Administración de la OIT (Convenio 116).

Sin embargo, la Corte no se ha limitado a estos instrumentos, de hecho ha sobrepasado ampliamente los criterios formales del Art. 93 estableciendo otras reglas que le permiten integrar instrumentos que a primera vista no cabrían en los parámetros del citado artículo.

Así por ejemplo, ha incluido dentro del Bloque: la Convención contra la Tortura y Otros Tratos o Penas Crueles, Inhumanos o Degradantes (Corte Constitucional, C-578/95, p. 42) ${ }^{23}$, y la Convención Interamericana sobre Desaparición Forzada de Personas'" (Corte Constitucional, Sent. C-580/02 $)^{24}$. Si bien el primero, tiene un lazo muy íntimo con el derecho a la integridad física, para poder incluir el segundo, sobre desaparición forzada, la Corte tuvo que esgrimir un argumento más complejo.

Según la Corte:

(...) no obstante la Convención Interamericana sobre Desaparición Forzada de Personas no es en sí un tratado de derechos humanos sino un mecanismo de erradicación del delito, comparte con aquellos el mismo fin protector de los derechos esenciales de las persona, ya que reconoce los derechos humanos y establece mecanismos que contribuyen en gran medida a su protección. Por eso, atendiendo el artículo 94 de la carta, hacen parte del bloque de constitucionalidad, las garantías adicionales de la Convención, que no estén expresas o adscritas directamente en la constitución. (Sent. T- 419/03) 
En ese mismo sentido, la Corte ya había incluido a la "Convención para la Prevención y la Sanción del Delito de Genocidio" en la sentencia C 177 /2001.

Pero la Corte no ha hecho referencia únicamente a Tratados, también ha incluido dentro del Bloque, instrumentos que no cumplen con el requisito de ser Tratados en el sentido del derecho internacional y que por ende no han tenido oportunidad de ser ratificados en Colombia. Es el caso de la Declaración Universal de los Derechos Humanos, citada en sentencias como la T-1211/00, C-1188/05. Y a la cual se hace referencia directa en la C-505/01, en donde la Corte establece que la Libertad de investigación consagrada en el artículo 19 de la Declaración Universal de los Derechos Humanos se encuentra integrada a la legislación interna por virtud de su vinculación al bloque de constitucionalidad (p. 35). En esa misma sentencia se inserta dentro del Bloque a la Declaración Americana de los Derechos del Hombre y del Ciudadano ${ }^{25}$, sobrepasando así el marco formal que imponía el Art. 93.

Incluso, al revisar los pactos de Ginebra, la Corte ha establecido, que respecto de esas normas no hace falta "la ratificación o adhesión que hayan prestado o dejado de prestar los Estados a los instrumentos internacionales que recogen dichos principios, ya que son normas de ius cogens" (Sent. C-578/95, p. 21) ${ }^{26}$, lo cual permite suponer, que un derecho o una obligación, cuyo contenido haya sido declarado internacionalmente como norma de ius cogens (es decir de imperatiividad superior) debe ser considerada como parte integral del Bloque de Constitucionalidad aunque no medie ningún tratado ratificado por Colombia.

Más allá de todo esto, la Corte, en la sentencia C-200/02 ${ }^{27}$ establece la forma en que debe identificarse un derecho intangible.

Además del articulado de los instrumentos protectores de derechos humanos, para saber cuando un derecho adquiere el carácter de intangible, la Corte, en la sentencia C-802 de 2002 (pp. 71-72, párr. 1) (posteriormente reiterado en salvamento de voto a la sentencia C-1056/04 del Magistrado Álvaro Tafur Galvis. y en la sentencia T-1319/01 M.P. Rodrigo Uprimny Yépez.) estableció que se debe observar las siguientes reglas:

1. Cuando el contenido de los derechos expresamente excluidos de restricción excepcional involucra no uno sino un conjunto de prerrogativas que guardan relación entre sí, todas éstas quedan cobijadas por la salvaguarda.

2. Dada la prohibición que tienen los Estados de proferir medidas de excepción incompatibles con otras normas internacionales, se amplía también el número de derechos excluidos, a menos que en los instrumentos suscritos existan previsiones sobre su suspensión en los mismos términos de los artículos 27 de la Convención y $4^{\circ}$ del Pacto.

3. Dada la vigencia de las garantías judiciales en los estados de excepción, ellas, especial los recursos de amparo y de habeas corpus, también están excluidas de la restricción de su ejercicio.

Hasta aquí se han analizado los instrumentos que hacen parte del Bloque, sin embargo, la Corte ha establecido también que para que el inciso 2 del art. 93 tenga pleno efecto, es necesario que las interpretaciones de los órganos autorizados por los instrumentos que hacen parte del Bloque, también sean parte del Bloque, sirviendo para la correcta interpretación de los derechos consignados y garantizando así la coherencia del sistema colombiano con el Derecho Internacional.

Interpretaciones de la Comisión Interamericana de Derechos Humanos, la Corte Interamericana de Derechos Humanos y el Comité de Derechos Humanos de Naciones Unidas sobre el Pacto de San José y la Convención Internacional de Derechos Civiles y Políticos (Corte Constitucional, Sent. T-1319/01). 
En la citada sentencia de la corte se consideró que

(...) el bloque de constitucionalidad relativo a la libertad de expresión ha de estar integrado por las normas internacionales, en particular el Pacto de San José y la Convención Internacional de Derechos Civiles y Políticos, junto con las interpretaciones que de tales textos han presentado la Comisión Interamericana de Derechos Humanos, la Corte Interamericana de Derechos Humanos y Comité de Derechos Humanos de Naciones Unidas. También ha de otorgarse un peso distinto a las Opiniones, pues la naturaleza judicial de la Corte Interamericana de Derechos Humanos, y su competencia sobre Colombia, implica que sus opiniones, más que tenidas en cuenta, no pueden ser ignoradas internamente" (p. 19)

Estas interpretaciones se aplican atendiendo el principio de favorabilidad, que obliga a adoptar la interpretación que más beneficie la protección de los derechos humanos.

Una de las interpretaciones que ha hecho la Corte Interamericana y que tiene aplicación en el ámbito interno, es respecto a los plazos en que se lleven a cabo las investigaciones dentro del proceso penal, los cuales deben responder al criterio de razonabilidad. Según esa Corporación, se deben atender tres elementos para saber si el plazo de la investigación ha sido o no razonable. Esos elementos son: la complejidad del asunto, la actividad procesal del interesado y la conducta de las autoridades públicas. (Corte Constitucional, Sent. C-1154/05)

\section{Recomendaciones de órganos de control}

Los órganos de control también son competentes para emitir recomendaciones $\mathrm{y}$, en ocasiones son vinculantes. Es el caso, por ejemplo, de las que profiere la Comisión Interamericana de Derechos Humanos: "La
Comisión es competente, en los términos de las atribuciones que le confieren los artículos 41 y 42 de la Convención, para calificar cualquier norma del derecho interno de un Estado Parte como violatoria de las obligaciones que éste ha asumido al ratificarla o adherir a ella"; "39. Como consecuencia de esta calificación, podrá la Comisión recomendar al Estado la derogación o reforma de la norma violatoria...". Por último, "Todos los órganos de los Estados Partes tienen la obligación de cumplir de buena fe las recomendaciones emitidas por la Comisión, no pudiendo ésta establecer el modo de ejecutarlas a nivel interno (...) siendo por tanto el Estado (...) el que debe determinar la forma de cumplir con las mismas" (CIDH, 1996, párr. 102).

El Comité de Libertad Sindical es un órgano de control de la OIT; confronta las situaciones de hecho que se le presentan o las normas internas de los Estados, con las normas internacionales aplicables según los Tratados ratificados por los Estados involucrados (en este caso, la Constitución de la OIT y los Convenios sobre libertad sindical); luego, formula recomendaciones y las somete al Consejo de Administración, ya que éste es el órgano que puede emitir recomendaciones de carácter vinculante según las normas que rigen la Organización. Colombia está obligada, en virtud de su calidad de Estado Parte del Tratado Constitutivo de la OIT, a acatar las recomendaciones del Consejo de Administración (arts. 24 y ss). (Corte Constitucional, Sent. T-568/99, p. 34) ${ }^{28}$.

Aunque esas recomendaciones no sean vinculantes de manera directa, igualmente crean unas obligaciones para el Estado vinculado, las cuales son: "deben 1) ser acogidas y aplicadas por las autoridades administrativas; 2) servir de base para la presentación de proyectos legislativos; y 3) orientar el sentido y alcance de las órdenes que el juez de tutela debe impartir para restablecer los derechos violados o amenazados en ése y los casos que sean similares" (p. 36). 
Principios rectores de los informes emitidos por los órganos de la ONU que tienen que ver con la protección de derechos humanos (Corte Constitucional, Sent. C-327/01, p.31) ${ }^{29}$

En la sentencia analizada se habla específicamente de los principios rectores del desplazamiento interno, consagrados en el informe del Representante Especial del Secretario General de Naciones Unidas en el Tema de Desplazamientos internos de Personas, y se establece que aquellos informes hacen parte del bloque de constitucionalidad en sentido lato, para resolver cada caso en concreto.

Además, si son preceptos que reiteran normas incluidas en tratados de Derechos Humanos o de Derecho Internacional Humanitario, algunos de los Principios Rectores pueden tener verdadero rango o jerarquía constitucional, al integrar el Bloque de Constitucionalidad en estricto sentido, de tal forma que sirven de parámetro para evaluar la constitucionalidad de las leyes. Por lo tanto, el Principio Rector No. 29 relativo al derecho de los desplazados al restablecimiento, forma parte del Bloque en sentido estricto, por recoger y reiterar varios tratados de derechos humanos relativos a los derechos económicos, sociales y culturales (Corte Constitucional, Sent. T-602/03, p. 30, párr. 1).

Según los tratados internacionales, los derechos de los niños prevalecen sobre los de las demás personas, y algunos de los que no se entienden como fundamentales para los demás, se entenderán fundamentales para los niños (C.C., T-1008/04).

Igualmente encontramos instrumentos internacionales de protección de derechos de los niños con algún tipo de discapacidad, como son: Convenio sobre la Readaptación Profesional y el Empleo de Personas Inválidas de la OIT; Declaración de los Derechos del Retrasado Mental; Declaración de los Derechos de los Impedidos de las Naciones Unidas; el Programa de Acción Mundial para las Personas con
Discapacidad; El Protocolo Adicional de la Convención Americana sobre Derechos Humanos en Materia de Derechos Económicos, Sociales y Culturales "Protocolo de San Salvador"; Los Principios para la Protección de los Enfermos Mentales y para el Mejoramiento de la Salud Mental; La Convención Interamericana para la Eliminación de todas las formas de Discriminación contra las Personas con Discapacidad, etc. (Corte Constitucional, Sent. T-1015/05, p. 34)

Las Reglas de Beijing Y Reglas de las Naciones Unidas para la Protección de Menores Privados de la Libertad (C.C., C203/05): Hacen parte del bloque de constitucionalidad, y en ellas se nombran, desarrollan e integran las diferentes reglas con relación a la protección de derechos fundamentales y la situación del menor delincuente. Se trata de estándares mínimos que reflejan, en conjunto, a las diversas garantías que el ordenamiento internacional de los derechos humanos reconoce a los menores de edad. Esas reglas hacen parte del Bloque de Constitucionalidad y son obligatorias por tratarse de una resolución de la Asamblea General de las Naciones Unidas.

También hacen parte del Bloque las Reglas de las Naciones Unidas para la Protección de Menores Privados de la Libertad, protegiéndose con ellas los derechos humanos y las libertades fundamentales de los menores que se encuentren en esa situación.

\section{Otros instrumentos que hacen parte del bloque}

Además de los tratados sobre derechos humanos intangibles ratificados por Colombia, es posible que otros instrumentos, internos e internacionales hagan parte del Bloque. Estos instrumentos son:

\section{Leyes estatutarias}

La Corte ha manifestado que la Ley Estatutaria sobre los estados de excepción hace 
parte del Bloque. "La citada ley, junto a las normas de la Constitución, integra el Bloque de Constitucionalidad que sirve para decidir la constitucionalidad o inconstitucionalidad de los decretos legislativos que se dicten al amparo de los estados de excepción" (Corte Constitucional, Sent. C-578/95, p. 28$)^{30}$.

No todo contenido de una ley estatutaria se entiende integra el bloque de constitucionalidad lato sensu, pues esto solo es viable a través de un mandato expreso de la Constitución. (C.C., C-708/99, P.14)

\section{Bloque de constitucionalidad en estados de excepción}

Al respecto, la Corte Constitucional ha expresado que "en el caso del derecho constitucional de excepción, el bloque de constitucionalidad está conformado por el Texto Superior, los instrumentos de derecho internacional humanitario, los tratados que consagran derechos humanos y la prohibición de suspensión durante los estados de excepción y la ley estatutaria de tales estados (Ley $137 \mathrm{de}$ 1993)" (Sent. C-802/02, p. 68).

\section{Tratados limítrofes}

Según la jurisprudencia de la Corte, hacen parte del Bloque debido a que el artículo 101 de la Carta, al definir los límites territoriales del Estado colombiano remite por completo a los tratados internacionales sobre la materia suscritos por Colombia.

Como ejemplo, se encuentra la Convención sobre la Plataforma Continental, suscrita en Ginebra el 29 de abril de 1958 e incorporada al derecho colombiano por la Ley $9^{a}$ de 1961 , en cuanto establece las reglas para delimitar la plataforma continental de los Estados ribereños y los derechos que éstos pueden ejercer sobre esa área submarina, hace parte del bloque de constitucionalidad lato sensu, por lo tanto, las normas que expidan las autoridades públicas no pueden contravenirlos a riesgo de ser declaradas inexequibles por violar el artículo 101 del Estatuto Superior. Sin embargo, es menester precisar que, aun cuando se conviertan en parámetro para llevar a cabo el control de constitucionalidad de las leyes, los tratados sobre límites no tienen valor constitucional sino un valor normativo similar al de las leyes orgánicas y las leyes estatutarias, es decir, ostentan una jerarquía intermedia entre la Constitución y las leyes ordinarias (Corte Constitucional, Sent. C-191/98) $)^{31}$.

\section{Pacto Andino (decisión 351 de 1993, Acuerdo de Cartagena) - Derechos Morales de Autor.}

En la medida en que el Acuerdo de Cartagena contiene el Régimen Común sobre derecho de autor y conexos, dado que regula los derechos morales de autor, que son, según considera la Corte, derechos fundamentales, sostiene la Honorable Corte que "a la luz de lo dispuesto en el artículo 93 de la C.P. se incorpora al bloque de constitucionalidad" (Corte Constitucional, Sent. C- $1490 / 00)^{32}$.

Es de anotar que solamente integra el Bloque en lo que se refiere a los derechos morales de autor, ya que se consideran derechos de rango fundamental, en cuanto la facultad creadora del hombre, la posibilidad de expresar las ideas o sentimientos de forma particular, su capacidad de invención, su ingenio y en general todas las formas de manifestación del espíritu, son prerrogativas inherentes a la condicional racional propia de la naturaleza humana, y a la dimensión libre que de ella se deriva. No ocurre lo mismo con los derechos patrimoniales de autor, los cuales no se consideran fundamentales.

\section{Normas que no hacen parte del bloque}

En la sentencia C-327/97, con ponencia del magistrado Fabio Morón Díaz, se establece que "si bien es cierto que los tratados internacionales vigentes en Colombia encuentran un incuestionable fundamento en normas constitucionales, ello 
no significa que todas sus normas integran el bloque de constitucionalidad y sirven de fundamento para realizar el control de constitucionalidad de las leyes que lleva a cabo esta Corporación "en los estrictos y precisos términos" del artículo 241 del Estatuto Superior. Una cosa es que las normas de los tratados internacionales tengan fundamento constitucional y otra, por entero diferente, que se hallen incorporadas al bloque de constitucionalidad y que deban ser tenidas en cuenta en el momento de decidir si una ley se ajusta o no a los preceptos de la Carta".

De manera más concreta indicó que: "Los tratados internacionales no constituyen por el solo hecho de serlo, parte del bloque de constitucionalidad y, por lo tanto, elemento de juicio para el examen de constitucionalidad de una norma. Ello significa que, en principio, no constituye motivo suficiente para la declaración de inconstitucionalidad de una norma legal el hecho de que ella se oponga a lo acordado en un trato internacional" (Corte Constitucional, Sent. C-358/97, p. 102)..$^{33}$

La Corte ha expresado que ni los tratados de integración económica ni el derecho comunitario integran el bloque de constitucionalidad, como quiera que "su finalidad no es el reconocimiento de los derechos humanos sino la regulación de aspectos económicos, fiscales, aduaneros, monetarios, técnicos, etc., de donde surge que una prevalencia del derecho comunitario andino sobre el orden interno, similar a la prevista en el artículo 93 de la Carta, carece de sustento" (C.C.,C-256/98). ${ }^{34}$

\section{Conclusiones}

El Bloque de Constitucionalidad, herramienta francesa incorporada en nuestro sistema jurídico a partir del art. 93 de la Constitución de 1991, representa un importante elemento de coherencia frente a un sistema monista constitucional, que pone a las normas constitucionales por encima de los tratados internacionales.
Gracias al Bloque de Constitucionalidad, los tratados en materia de Derechos Humanos tienen un rango constitucional, que les permite servir de filtro de exequibilidad a las normas de rango inferior, garantizando el cumplimiento del derecho internacional, al menos en lo que respecta la materia de estos tratados.

Pero en Colombia, en los últimos años, las fuentes de creación del derecho han variado; hoy se tiene claramente aceptado, que la jurisprudencia de la Corte Constitucional es una fuente formal del derecho, al menos constitucional y en ese sentido, es indispensable estudiar la jurisprudencia para entender el alcance y contenido del Bloque.

Bajo una revisión exhaustiva de la jurisprudencia Constitucional, es posible concluir que el Bloque de Constitucionalidad se ha convertido en una sofisticada regla de exequibilidad en la cual es posible distinguir dos tipos de Bloque. Por una parte, el Bloque strictu sensu, es aquel que integra materialemente las normas de los tratados que cumplen con el inciso primero del Art. $93 \mathrm{y}$, en ese sentido, esas normas adquieren rango constitucional. El Bloque lato sensu, es el que componen normas que si bien no pasan a hacer parte material de la Constitución, son fuentes auxiliares de interpretación, a cuya luz deberán leerse los derechos consagrados en la Constitución, a la hora de hacer la revisión de constitucionalidad de algunas leyes.

Pero fuera de ello, es posible leer que la jurisprudencia de la Corte ha sobrepasado el umbral del art. 93, al menos desde tres perspectivas diferentes. En primer lugar, desde el funcionamiento del Bloque, al establecer que no solamente es útil para revisar la exequibilidad de otras normas de inferior jerarquía, sino que puede servir incluso como sustento de una acción tutelar. En segundo lugar, desde el contenido del Bloque, puesto integra, vía jurisprudencial, una serie de normas que no cumplen con los requisitos del art. 93, entre las cuales se puede citar leyes estatutarias, tratados relativos a límites territoriales o 
tratados de derecho internacional humanitario y convenios de la OIT. Estos instrumentos, que no contienen derechos irrestringibles en estados de excepción, han sido integrados reiteradamente en el Bloque de Constitucionalidad, por una forma extensiva de interpretación del art. 93 superior. En tercer lugar, el párrafo 2 del art. 93, ha sido extendido, no solo a normas que no cumplan con los requisitos del primer inciso, sino igualmente a las consideraciones y decisiones de los órganos de control de los tratados de Derechos Humanos.

Este último punto, resulta de gran importancia para el estudio en cuestión, puesto que bajo la lógica de la Corte Constitucional es necesario integrar la interpretación interna de los derechos fundamentales, con la interpretación internacional que se haga de los mismos, a fin de garantizar el cumplimiento de las obligaciones internacionales $\mathrm{y}$ actuar de forma coherente con la visión general de los Derechos Humanos. Ello implica que las decisiones que los órganos internacionales toman con respecto a Colombia, adquieren un valor especial, por hacer parte del Bloque de Constitucionalidad (lato sensu).

En lo que respecta al Sistema Interamericano en particular, la Corte ha relevado el valor jurídico de las decisiones de la Corte Interamericana sobre Colombia e incluso, ha tenido en cuenta en sus sentencias las consideraciones de la Comisión interamericana al interpretar los derechos contenidos en la Convención. Es una situación de compromiso que convierte al país en un Estado sumamente comprometido con la protección de los Derechos Humanos, al menos en cuanto al respeto de los compromisos internacionalmente adquiridos.

Los contradictores de la evolución jurisprudencial de la Corte sostienen que la inseguridad jurídica que origina un Bloque de Constitucionalidad sin reglas claras conduce más a una violación de los derechos vía vulneración del Estado de Derecho, que a la garantía que puede dar una normatividad clara y firme. Lo cierto es que, si bien hay que admitir que la Corte ha interpretado muy ampliamente los criterios del art. 93, la interpretación solo ha tenido como finalidad fortalecer la protección de los Derechos Humanos, y tratar de solventar el inconveniente de un sistema jurídico de actitud monista constitucional. Al integrar los tratados, sus interpretaciones y las decisiones que surgen de su vigilancia, la Corte garantiza que los mismos serán respetados por las normas internas, anulando las posibilidades de incurrir en responsabilidad internacional por falta de adecuación del derecho interno. Además, la Corte ha sido cuidadosa al establecer criterios aceptables para la integración de tratados que en principio no cumplen con los requisitos del Art. 93, y por eso la existencia de un Bloque lato sensu, se traduce en una herramienta valiosa que puede, en última instancia, servir de la misma forma en que sirve el Bloque strictu sensu.

\section{Notas}

1 Revisión de Constitucionalidad del "Protocolo adicional a los Convenios de Ginebra del 12 de agosto de 1949, relativo a la protección de las víctimas de los conflictos armados sin carácter internacional (Protocolo II)" hecho en Ginebra el 8 de junio de 1977, y de la Ley 171 del 16 de diciembre de 1994, por medio de la cual se aprueba dicho Protocolo.

Reiterado en la sentencia C-177/01.

${ }^{2}$ Reiterado en las sentencias de la Corte Constitucional: C-578/95, C-327/97, C-358/97, T1211/00, C-177/01, C-067/03, C-962/03, C-1188/ 05, C-028/06.

${ }^{3}$ Ver también sentencia T-666/04, C-148/05.

${ }^{4}$ Ratificado en las sentencias: C-225/95, C578/95, C-327/97, Auto 078/99, C-582/99, T-1211/ 00, C-1490/00, C-1635/00, C-177/01, C-774/01, C200/02, C-580/02, C-148/05, C-820/05, C-1001/05.

\footnotetext{
${ }^{5}$ Sentencia T-1319/01 M.P Rodrigo Uprimny Yépez. Reiterado en sentencias: SU-058/03, C067/03, T-666/04, C-148/05.
} 
${ }^{6}$ Reiterado en sentencia C-820/05.

${ }^{7}$ Reiterado en la sentencias: C-1490/00, C774/01, C-067/03, C-129/04, C-148/05, C-592/05.

${ }^{8}$ Reiterado en la sentencia C-708/99.

${ }^{9}$ Sentencias C-600 de 1995, C-287 de 1997, C-337 de 1993.

${ }^{10}$ Sentencias C-179 de 1994, C-578 de 1995.

${ }^{11}$ Reiterado en las sentencias: C-1490/00, C200/02, C-148/05, C-592/05.

${ }^{12}$ Por límites de espacio, no es posible consignar en este artículo las consideraciones de la Corte Constitucional frente a cada uno de los instrumentos, sin embargo, se citan las sentencias hito en que fueron enunciados como parte del Bloque.

${ }^{13}$ Reiterado en las sentencias T-256/00, T786/03, C-962/03, C-782/05, C-1153/05, C-028/ 06, C-043/06, C-046/06, C-123/06, T-578/06.

${ }^{14}$ Ver sentencias T $-1211 / 00, \mathrm{C}-038 / 04, \mathrm{~T}-$ 642/04, T-666/04, T-697/04, C-035/05, C-1188/ 05, C-043/06.

${ }^{15}$ Reiterado en sentencias: C-962/03, C-1194/05

${ }^{16}$ Reiterado en sentencias: C-997/04, T-1008/ 04, T-1061/04, T-1015/05.

${ }^{17}$ Ver también sentencia C-1188/05.

${ }^{18}$ Ver también sentencia C-1188/05.

${ }^{19}$ Reiterado en sentencias T-666/04, C-035/ 05, Salvamento de Voto a la sentencia C-177/05.

${ }^{20}$ Reiterado en las sentencias: C-385/00, C567/00, C-797/00, C-1491/00, C-1188/05, C-043/ 06, T-285/06.

${ }^{21}$ Ver entre otras la sentencia C-035/05. M.P. Rodrigo Escobar Gil.
${ }^{22}$ Reiterado en sentencia T-048/02, C-575/06.

${ }^{23}$ Reiterado en sentencia C-1076/02.

${ }^{24}$ Reiterado en sentencia: T-419/03.

${ }^{25}$ Reiterado en sentencias: C-962/03, C-1188/ 05, C-043/06.

${ }^{26}$ Reiterado en sentencia: SU-256/99.

${ }^{27}$ Ver también sentencia SU-058/03.

${ }^{28}$ Reiterado en la sentencia: T-1211/00.

${ }^{29}$ Reiterado en sentencias: T-268/03, T-419/ 03, T-602/03.

${ }^{30}$ Reiterado en la sentencia: C-135/96, C-993/04.

${ }^{31}$ Reiterado en la sentencias C-1022/99, C067/03.

${ }^{32}$ Reiterado en las sentencias: C-053/01, C988/04, C-118/05, C-339/06.

${ }^{33}$ Reiterado en sentencia: C-191/98, C-582/ 99, C-774/01, C-129/04, C-988/04, C-1197/05.

${ }^{34}$ Reiterado en la sentencia C-582/99, C-988/ 04, C1118/05.

\section{Referencias}

Arango-Olaya, M. (S.F.), "El bloque de constitucionalidad en la jurisprudencia de la Corte Constitucional Colombiana" [en línea], disponible en: http://dspace.icesi.edu.co/ dspace/ handle/item/949, recuperado: 12 de junio de 2007.

Estrada-Vélez, S. I.. (2005), Los principios jurídicos y el Bloque de Constitucionalidad, Medellín, Universidad de Medellín.

Góngora-Mera, M. E. (2007), El bloque de constitucionalidad en Argentina y su 
relevancia en la lucha contra la impunidad. [en línea], disponible en: http:// www.menschenrechte.org/beitraege/ lateinamerika/Argentina_bloque_y_ amnistia.pdf, recuperado: 04 de mayo de 2007.

Pinella, J. (1994), Sistema de fuentes y bloque de constitucionalidad, Barcelona, Bosch.

Ramelli, A. (2000), La constitución colombiana $y$ el Derecho Internacional Humanitario, Bogotá, Universidad Externado de Colombia.

(2003), "Sistema de Fuentes del Derecho Internacional Público Bloque de Constitucionalidad", en: Eduardo Montealegre Lynett (Coor.), Anuario de Derecho Constitucional, Primera edición. Bogotá, Universidad Externado de Colombia.

Rey Cantor, E. (2006), -El bloque de Constitucionalidad, aplicación de tratados internacionales de derechos humanos", en Revista del Centro de Estudios Constitucionales de la Universidad de Talca, 4 (2), pp. 299-334.

Rubio - Llorente, A. (1991), El bloque de Constitucionalidad, Madrid, Universidad de Sevilla, Civitas.

Uprimny, Rodrigo (2000), "E1 bloque de Constitucionalidad en Colombia, un análisis jurisprudencial y un ensayo de sistematización doctrina", [en línea], disponible en: http:/ /www.djs.org.co/equipo/publicaciones. php?aut_id=8, recuperado: 1 de marzo de 2007.

(2004). "Bloque de Constitucionalidad, Derechos Humanos y nuevo procedimiento penal", [en línea], disponible en: http:// www.djs.org.co/equipo/publicaciones. php?aut_id=8, recuperado: 14 de marzo de 2007.
Corte Interamericana de Derechos Humanos, (1996, 15 de octubre), Informe Anual de la Comisión Interamericana de Derechos Humanos Caso 11.430, México.

\section{Jurisprudencia:}

Corte Constitucional, Sentencia C-574/92, Magistrado Ponente: Ciro Angarita Barón Corte Constitucional, Sentencia C-295/93, Magistrado Ponente: Carlos Gaviria Díaz Corte Constitucional, Sentencia C-337/93, Magistrado Ponente: Vladimiro Naranjo Mesa Corte Constitucional, Sentencia C-179/94, Magistrado Ponente: Carlos Gaviria Díaz Corte Constitucional, Sentencia C-225/95, Magistrado Ponente: Alejandro Martínez C. Corte Constitucional, Sentencia C-578/95, Magistrado Ponente: Eduardo Cifuentes Muñoz Corte Constitucional, Sentencia C-135/96, Magistrado Ponente: Jorge Arango Mejía

Corte Constitucional, Sentencia C-032/97, Magistrado Ponente: Hernando Herrera Vergara Corte Constitucional, Sentencia C-251/97, Magistrado Ponente: Alejandro Martínez Caballero Corte Constitucional, Sentencia C-287/97, Magistrado Ponente: Eduardo Cifuentes Muñoz Corte Constitucional, Sentencia C-327/97, Magistrado Ponente: Fabio Morón Díaz

Corte Constitucional, Sentencia C-358/97, Magistrado Ponente: Eduardo Cifuentes Muñoz Corte Constitucional, Sentencia C-658/97, Magistrado Ponente: Vladimiro Naranjo Mesa Corte Constitucional, Sentencia C-191/98, Magistrado Ponente: Eduardo Cifuentes Muñoz Corte Constitucional, Auto 078/99, Magistrado Ponente: Vladimiro Naranjo Mesa

Corte Constitucional, Sentencia SU-256/99, Magistrado Ponente: José Gregorio Hernández Corte Constitucional, Sentencia T-260/99, Magistrado Ponente: Carlos Gaviria Díaz

Corte Constitucional, Sentencia C-708/99, Magistrado Ponente: Álvaro Tafur Galvis Corte Constitucional, Sentencia T-568/99, Magistrado Ponente: Carlos Gaviria Díaz Corte Constitucional, Sentencia C-582/99, Magistrado Ponente: Alejandro Martínez Caballero 
Corte Constitucional, Sentencia C-708/99, Magistrado Ponente: Álvaro Tafur Galvis

Corte Constitucional, Sentencia C-1022/99, Magistrado Ponente: Alejandro Martínez Caballero

Corte Constitucional, Sentencia T-256/00, Magistrado Ponente: José Gregorio Hernandez Corte Constitucional, Sentencia C-385/00, Magistrado Ponente: Eduardo Cifuentes Muñoz Corte Constitucional, Sentencia C-567/00, Magistrado Ponente: Alfredo Beltrán Sierra Corte Constitucional, Sentencia C-797/00, Magistrado Ponente: Antonio Barrera Carbonell Corte Constitucional, Sentencia T-1211/00, Magistrado Ponente:Alejandro Martínez caballero Corte Constitucional, Sentencia C-1490/00, Magistrado Ponente: Luis Eduardo Mejía Jiménez Corte Constitucional, Sentencia C-1491/00, Magistrado Ponente: Fabio Morón Díaz

Corte Constitucional, Sentencia C-1635/00, Magistrado Ponente: José Gregorio Hernandez Corte Constitucional, Sentencia C-053/01, Magistrado Ponente: Cristina Pardo

Corte Constitucional, Sentencia C-177/01, Magistrado Ponente: Fabio Morón Díaz

Corte Constitucional, Sentencia C-327/01, Magistrado Ponente: Marco Gerardo Monroy Cabra Corte Constitucional, Sentencia C-501/01, Magistrado Ponente: Jaime Córdoba Triviño Corte Constitucional, Sentencia C-505/01, Magistrado Ponente: Marco Gerardo Monroy Cabra Corte Constitucional, Sentencia C-606/01, Magistrado Ponente: Marco Gerardo Monroy Cabra Corte Constitucional, Sentencia C-774/01, Magistrado Ponente: Rodrigo Escobar Gil

Corte Constitucional, Sentencia T-1303/01, Magistrado Ponente: Marco Gerardo Monroy Cabra Corte Constitucional, Sentencia T-1319/01, Magistrado Ponente: Rodirgo Uprimny

Corte Constitucional, Sentencia T-048/02, Magistrado Ponente: Álvaro Tafur Galvis

Corte Constitucional, Sentencia C-200/02, Magistrado Ponente: Álvaro Tafur Galvis Corte Constitucional, Sentencia C-317/02, Magistrado Ponente: Clara Inés Vargas

Corte Constitucional, Sentencia C-580/02, Magistrado Ponente: Rodrigo Escobar Gil
Corte Constitucional, Sentencia C-802/02, Magistrado Ponente: Jaime Córdoba Triviño Corte Constitucional, Sentencia T-1064/02, Magistrado Ponente: Alfredo Beltrán Sierra Corte Constitucional, Sentencia T-1068/02, Magistrado Ponente: Jaime Araujo Rentería Corte Constitucional, Sentencia C-1076/02, Magistrado Ponente: Clara Inés Vargas Hernández Corte Constitucional, Sentencia C-067/03, Magistrado Ponente: Marco Gerardo Monroy Cabra Corte Constitucional, Sentencia SU-058/03, Magistrado Ponente: Dr. Eduardo Montealegre Corte Constitucional, Sentencia T-268/03, Magistrado Ponente: Marco Gerardo Monroy Cabra Corte Constitucional, Sentencia T-419/03, Magistrado Ponente: Alfredo Beltrán Sierra Corte Constitucional, Sentencia T-558/03, Magistrada Ponente: Clara Inés Vargas

Corte Constitucional, Sentencia T-602/03, Magistrado Ponente: Alfredo Beltrán Sierra Corte Constitucional, Sentencia C-692/03, Magistrado Ponente: Marco Gerardo Monroy Cabra Corte Constitucional, Sentencia T-786/03, Magistrado Ponente: Marco Gerardo Monroy Cabra Corte Constitucional, Sentencia T-955/03, Magistrado Ponente: Carlos Gaviria Díaz

Corte Constitucional, Sentencia C-962/03, Magistrado Ponente: Alfredo Beltrán Sierra Corte Constitucional, Sentencia C-038/04, Magistrado Ponente: Eduardo Montealegre Lynett Corte Constitucional, Sentencia C-129/04, Magistrado Ponente: Marco Gerardo Monroy Cabra Corte Constitucional, Sentencia T-642/04, Magistrado Ponente: Rodrigo Uprimny Yepes Corte Constitucional, Sentencia T-666/04, Magistrado Ponente: Álvaro Tafur Galvis Corte Constitucional, Sentencia T-697/04, Magistrado Ponente: Rodrigo Uprimny Yepes Corte Constitucional, Sentencia T-891/04, Magistrado Ponente: Jaime Araujo Rentería Corte Constitucional, Sentencia C-988/04, Magistrado Ponente: Humberto Sierra Porto Corte Constitucional, Sentencia C-993/04, Magistrado Ponente: Jaime Araujo Rentería Corte Constitucional, Sentencia C-997/04, Magistrado Ponente: Jaime Córdoba Triviño Corte Constitucional, Sentencia C-1056/04, Magistrado Ponente: Álvaro Tafur Galvis 
Corte Constitucional, Sentencia C-035/05, Magistrado Ponente: Rodrigo Escobar Gil

Corte Constitucional, Sentencia C-148/05, Magistrado Ponente: Álvaro Tafur Galvis

Corte Constitucional, Sentencia C-177/05, Magistrado Ponente: Manuel José Cepeda

Corte Constitucional, Sentencia C-203/05, Magistrado Ponente: Manuel José Cepeda Espinosa Corte Constitucional, Sentencia C-401/05, Magistrado Ponente: Manuel José Cepeda Espinosa Corte Constitucional, Sentencia C-592/05, Magistrado Ponente: Álvaro Tafur Galvis

Corte Constitucional, Sentencia C-782/05, Magistrado Ponente: Alfredo Beltran Sierra Corte Constitucional, Sentencia C-820/05, Magistrado Ponente: Clara Inés Vargas Hernández Corte Constitucional, Sentencia C-1001/05, Magistrado Ponente: Álvaro Tafur Galvis Corte Constitucional, Sentencia T-1015/05, Magistrado Ponente: Margo Gerardo Monroy Cabra Corte Constitucional, Sentencia C.1118/05, Magistrado Ponente: Clara Inés Vargas Hernández Corte Constitucional, Sentencia C-1153/05, Magistrado Ponente: Marco Gerardo Monroy Cabra Corte Constitucional, Sentencia C-1154/05, Magistrado Ponente: Manuel José Cepeda Espinosa Corte Constitucional, Sentencia C-1188/05, Magistrado Ponente: Alfredo Beltrán Sierra Corte Constitucional, Sentencia C-1194/05, Magistrado Ponente: Alfredo Beltrán Sierra Corte Constitucional, Sentencia C-1197/05, Magistrado Ponente: Humberto Sierra Porto Corte Constitucional, Sentencia C-028/06, Magistrado Ponente: Humberto Sierra Porto Corte Constitucional, Sentencia ,C-043/06 Magistrado Ponente: Clara Inés Vargas Hernández Corte Constitucional, Sentencia C-046/06, Magistrado Ponente: Jaime Araujo Rentería Corte Constitucional, Sentencia C-118/06, Magistrado Ponente: Jaime Araujo Rentería Corte Constitucional, Sentencia C-123/06, Magistrado Ponente: Clara Inés Vargas Hernández Corte Constitucional, Sentencia T-285/06, Magistrado Ponente: Álvaro Tafur Galvis

Corte Constitucional, Sentencia C-339/06, Magistrado Ponente: Jaime Córdoba Triviño
Corte Constitucional, Sentencia C-575/06, Magistrado Ponente: Álvaro Tafur Galvis Corte Constitucional, Sentencia T-578/06, Magistrado Ponente: Manuel José Cepeda Hernández 